\title{
LA APORÍA DE AUSCHWITZ EN DER VORLESER, DE BERNHARD SCHLINK: JUSTICIA, CULPA Y SUPERACIÓN DEL PASADO EN LA LITERATURA
}

\author{
María del Carmen Balbuena Torezano \\ Indrid Cobos López \\ Universidad de Córdoba
}

\section{RESUMEN}

El presente trabajo aborda el estudio de la novela Der Vorleser, desde la perspectiva del contenido jurídico y de lo que este representa dentro de la concepción global de la obra, a través del texto original como fuente principal del análisis. Para ello, llevamos a cabo un análisis de tres ejes fundamentales relacionados entre sí: la jurisprudencia, la justicia y la validez de esa justicia; la culpa criminal, la culpa moral y la culpa colectiva; y el proceso judicial, la responsabilidad y el castigo. Todo ello nos servirá para determinar si es posible hablar de superación del pasado, entendiendo como tal los acontecimientos que tuvieron lugar en los campos de exterminio durante la II Guerra Mundial, o si por el contrario hemos de hablar de aporía legal e histórica plasmada en la novela de Schlink.

Palabras Clave: Vergangenheitsbewältigung, jurisprudencia, literatura alemana, conflicto generacional, aporía.

THE APORIA OF AUSCHWITZ IN DER VORLESER, BY BERNHARD SCHLINK: JUSTICE, GUILT AND OVERCOMING OF THE PAST IN THE LITERATURE

\section{Abstract}

This paper focuses on the analysis of the novel Der Vorleser (The Reader), from the point of view of its juridical content and relevance in the novel and the whole conception of the work, through the original text as main source of the analysis. In order to achieve our aims, we will study three focal points which are related: jurisprudence, justice and its (in)validity; guilty as a legal concept, moral guilt and collective guilt; and trial, criminal responsibility and criminal punishment. We will try to confirm if it is possible to speak of overcoming of the past (Vergangenheitsbewältigung), that is, those terrible crimes committed against Jews in extermination camps during the Second World War or if we can just speak of a legal and historical aporia shown by Schlink.

KeYwords: Vergangenheitsbewältigung, Jurisprudence, German literature, generation conflict, aporia. 


\section{INTRODUCCIÓN}

No son pocos los estudios que Der Vorleser ha generado desde su publicación en 1995; en efecto, la novela de Schlink ${ }^{1}$ pronto se convirtió en un fenómeno literario ${ }^{2}$, lo que llevó a su traducción a un total de veinticinco idiomas tan solo cinco años tras su publicación, momento en el que ya se habían vendido un millón de ejemplares en todo el mundo; a la concesión de numerosos premios y reconocimientos ${ }^{3}$; la repercusión mundial de la obra ha generado todo tipo de críticas: por un lado, sus detractores estiman que «apenas ha contribuido a hacernos entender el Holocausto y sus repercusiones» (Wirtz 2000), y achacan al autor que deje en el aire la sentencia dictada a Hanna, nunca pronunciada como tal por el juez en la novela, contribuyendo con ello a que la «univocidad de los actos jurídicos quede inmersa en un mar de imponderables» (Lewis 1997: 77); por otro lado, hay quienes alaban la obra de Schlink como ejemplo paradigmático de superación del pasado (Vergangenheitsbewältigung).

Desde el punto de vista académico, los trabajos sobre Der Vorleser han versado sobre la ficción del Holocausto en la literatura (Donahue 2001; Auer 2014), la jurisprudencia y el Derecho (Dreike 2002; Bonilla 2005; Ost 2006), el pasado, la

${ }^{1}$ Jurista y profesor universitario alemán, doctorado en Derecho por la Universidad de Friburgo, ha ocupado las cátedras de Derecho Constitucional y Derecho Administrativo en la Universidad de Bonn y de Derecho Público en la Humboldt Universität, hasta su jubilación en 2009. Como jurista ha ejercido como juez en el Tribunal de Renania del Norte-Westfalia en Münster hasta 2006. Esta doble condición de jurista y docente se ha traducido en una amplia obra literaria y jurídica. Así, entre sus obras de literatura cabe señalar las novelas Selbs Justiz (1987), Die gordischel Schleife (1988), Selbs Betrug (1992), Der Vorleser (1995), Liebesfruchten (2000), Selbs Mord (2001), Die Heimkehr (2006), Das Wochenende (2008) y Sommerlügen (2010). Como jurista es autor de numerosos ensayos, en los que analiza cuestiones de diversa índole, al tiempo que plantea sus posibles soluciones. En este sentido, Der Vorleser aborda la cuestión del genocidio nazi y los crímenes de guerra, la culpa y el castigo infligido a sus criminales, envolviendo la historia con una relación amorosa entre Hanna Schmitz, antigua guardiana del campo de concentración de Auschwitz, y Michael, un joven de 15 ańos. Ante la desaparición repentina de Hanna, Michael continúa sus estudios de Derecho, y vuelve a verla en un juicio al que acude junto a su profesor y los compañeros de clase, en el que Hanna, junto a otras guardianas, están siendo juzgadas por crímenes de guerra. En este momento se plantea la cuestión de la culpa moral, la culpa colectiva y la culpa jurídica, en la que Michael se verá envuelto como espectador directo de la historia más reciente de su país, y como «heredero» de la vergüenza de la generación de sus progenitores.

2 A este respecto, afirma Escobar (2005: 113): «El lector ha sido un éxito editorial de tal magnitud que quien se acerque al texto probablemente lo hará por recomendación de otro, y tal vez lo hará dotado de alguna idea del contenido de la obra».

${ }^{3}$ Entre otros, cabe destacar los siguientes: Premio Grinzane Cavour, Italia; Prix Laure Bataillon, Francia; Premio Hans Fallada, Neumünster; Evangelischer Buchpreis des Deutschen Verbandes; Premio especial del diario japonés Mainichi Shibun, Premio Heinrich Heine; del mismo modo, la obra ha sido incluida en el currículo escolar en Alemania y ha sido adaptada al cine por Stephen Daldry en 2008. En este trabajo utilizaremos como fuente principal la obra literaria en lengua alemana, si bien emplearemos, cuando lo estimemos necesario, la traducción al español realizada por M. Sáez y la adaptación cinematográfica de Stephen Daldry. 
culpa y la memoria colectiva (Schmitz 2002, Escobar 2005, Rubino 2015), las cuestiones históricas y sociológicas que subyacen a la obra (Fernández 2004), los conflictos éticos y morales (Reviglio 2010; Escobar-Jiménez 2017) o la literatura comparada (Hall 2006). Finalmente, desde el punto de vista de la recepción de la obra en España a través de la traducción, cabe señalar la tesis doctoral de Castillo (2016) ${ }^{4}$. En efecto, la recepción de Der Vorleser a través de la literatura y el cine supuso el «descubrimiento» de Schlink, hasta el momento poco conocido en Espańa; por otra parte, la historia contada desde la obra literaria y la obra fílmica no nos es ajena, si bien nos presenta la crudeza del nacionalsocialismo desde una perspectiva hasta ahora no tratada: la superación del pasado, la culpa, la justicia y la firme decisión de redimir los crímenes cometidos. En las páginas siguientes abordaremos el análisis de los principales conceptos jurídicos presentes en la parte central de la novela y su relación con la realidad histórica del momento al que hacen referencia, con especial incidencia en lo relativo a la jurisprudencia, la justicia, la validez, el concepto de culpa y la punibilidad de los crímenes cometidos.

\section{DER VORLESER: \\ DE LA OBRA LITERARIA A LA OBRA FÍLMICA}

Uno de los principales atractivos de Der Vorleser es la presentación, desde el inicio, de un tema recurrente en la literatura de posguerra: el conflicto intergeneracional que surge como consecuencia del fenómeno de «desnazificación» que tiene lugar en Alemania al terminar la II Guerra Mundial. La literatura de finales de los años 80 del pasado siglo ya contenía como temática la visión del mundo y este conflicto entre generaciones. Buena muestra de ello es Bronsteins Kinder, de Jurek Becker (1986), en la que Hans, un joven judío de 19 años, descubre que su padre, con la ayuda de otros dos judíos, mantuvo prisionero a su guardián del campo de concentración en un barracón alejado de todos. Fruto de este descubrimiento son las largas conversaciones con su padre, pero también con el que fuera su prisionero. Esta confrontación entre padres e hijos derivará en los años 90 en un tipo de literatura cuya temática principal será la Vergangenheitsbewältigung, esto es, el enfrentamiento crítico con el pasado y la superación del mismo. En las obras, pues, está presente la denominada «segunda generación» (die Nachgeborenen, die Nachkriegsgeneration) 5 . Así lo estima parte de la crítica (cit. en Heigenmoser 2010: 99ss.):

... Doch Schlink geht einen Schritt weiter: Er parallelisiert die vergleichsweise harmlose Schuld eines Nachgeborenen mit der Schuld der Älteren. Sein Demonstrationsobjekt ist kein Elternteil, insofern ist die Versuchanordnung weniger

\footnotetext{
4 Tesis doctoral realizada bajo la dirección de Balbuena Torezano.

5 En este sentido, podemos considerar Der Vorleser, también en su versión fílmica, una Bildungsroman, pues se nos muestra a un protagonista que crece vital y moralmente a lo largo de la historia.
} 
verfänglich. Aber die Botschaft gilt unmißverständlich beiden Generationen, die im selben Boot sitzen (Krause 1995).

[...] Die Liebesgeschichte zwischen der NS-Täterin und dem Nachgeborenen, der ihr Sohn sein könnte, list sich wie eine finster überspitzte Allegorie auf das Verhältnis zwischen Kriegs- und Nachkriegsgeneration in Deutschland. Der Roman fragt nach der Entstehung von Schuld auf der einen und der Grenze von Schuld und Unschuld auf der anderen Seite (Löhndorf 1995) ${ }^{7}$.

Der Vorleser von Bernhard Schlink ist die Entdeckung der Grauzonen. Er verschränkt die 'Vergangenheitsbewältigung〉 des Dritten Reiches mit jener der Studentenrevolte [.... (Mosler 1996) ${ }^{8}$.

«Der Vorleser» präsentiert in einer ins Extreme gesteigerten Form verstörende Erfahrung, mit der sich auch noch die heutige Enkelgeneration konfrontiert sehen kann: Auch der geliebte Großmutter, die Oma, ist auf die ein oder andere Weise «dabei» gewesen (Deißner y Lindeman 2007) .

Ese conflicto intergeneracional se muestra de forma más explícita en la segunda parte de la novela, cuando Michael describe a cada uno de los integrantes de las generaciones en conflicto: los progenitores, quienes de una u otra forma colaboraron y participaron del Tercer Reich; y, por otra parte, los estudiantes de esa nueva generación que había de juzgarlos (Schlink 1995: 87s.):

Unsere Eltern hatten im Dritten Reich ganz verschiedene Rollen gespielt. [...] Ich bin sicher, daß sie, soweit wir sie gefragt und sie uns geantwortet haben, ganz Verschiedenes mitzuteilen hatten. [...] Wir alle verurteilten unsere Eltern zu Scham, und wenn wir sie nur anklagen konnten, die Täter nach 1945 bei sich, unter sich geduldet zu haben ${ }^{10}$.

6 «... Pero Schlink va un paso más allá: confronta de forma paralela la culpa inocua de la segunda generación con la culpa de la primera generación. Su objetivo no es mostrar una cuestión de conflicto con el padre, de esta forma el método probatorio resulta algo menos embarazoso. Pero el mensaje resulta inequívoco para ambas generaciones, que están en el mismo barco». Traducción de las autoras.

7 «... La historia de amor entre la criminal nazi y el chico de esa segunda generación que podría ser su hijo se configura como una oscura y exagerada alegoría de la relación existente entre la generación de la guerra y la de la posguerra. La novela cuestiona por un lado los orígenes de la culpa y por el otro la frontera entre la culpa y la inocencia». Traducción de las autoras.

8 «El lector de Bernhard Schlink es el descubrimiento de las zonas grises. Entrelaza la superación del pasado del Tercer Reich con la revuelta estudiantil». Traducción de las autoras.

9 "El lector presenta una experiencia perturbadora en una forma extrema, con la que incluso la generación actual de nietos puede ser confrontada: incluso la adorada abuela ha estado "ahí" de una forma u otra». Traducción de las autoras.

10 «Nuestros padres habían desempeñado papeles muy distintos en el Tercer Reich. (...) Estoy seguro de que, a medida que les hubiéramos preguntado y nos habrían respondido muchas cosas diferentes (...). Todos condenamos a nuestros padres a la vergüenza si hubiéramos podido acusarlos de haber tolerado a los criminales después de 1945 entre ellos». Traducción de las autoras. 
En 1997, dos años después de la publicación de Der Vorleser, aparece su traducción al inglés bajo el título The Reader, lo que disparó su popularidad, hasta el punto de que Schlink se convierte en el primer escritor alemán entrevistado por Oprah Winfrey en su programa televisivo Oprah's Book Club en 1999, como consecuencia de que su novela es elegida libro del mes en Estados Unidos en marzo de ese mismo año.

Esta popularidad lleva al autor a vender los derechos de la obra para ser adaptada al cine a la productora hollywoodiense Miramax, y en 2008, a partir de un guion de David Hare, y bajo la dirección de Stephen Daldry, con fotografía de Roger Deakins y Chris Menges y música de Nico Muhly, la novela de Schlink fue llevada a la gran pantalla. La cinta, fruto de una coproducción entre Estados Unidos y Alemania, fue protagonizada por Kate Winslet (Hanna Schmitz), Ralph Fiennes (Michael Berg adulto) y David Kross (Michael Berg adolescente). En 2009 fue nominada al Óscar a la Mejor Película, y su protagonista recibió la estatuilla dorada a la Mejor Actriz. Otros personajes significativos, como el profesor Rohl, fueron encarnados por actores alemanes de la talla de Bruno Ganz. En España la película se estrenó el 13 de febrero de 2009, alcanzando un éxito de taquilla considerable.

\section{LA APORÍA DE DER VORLESER}

Tras la lectura detenida de la obra que aquí nos ocupa, podemos determinar, coincidiendo con Dreike (118), que Der Vorleser introduce al lector no instruido en Derecho en la problemática de la relación entre justicia, culpa y castigo, atendiendo al principio de la proporcionalidad, todo ello mediante el empleo de un discurso comprensible por quien lee la obra.

Uno de los objetivos que, a nuestro juicio, persigue la obra es, en primer lugar, que el lector comprenda, a través de la ficción, la magnitud del genocidio y por qué este llegó a producirse. Esta es, precisamente, la función de la literatura: exponer, a través de una realidad ficticia, la realidad histórica más execrable, envuelta en una historia de amor entre una mujer madura y joven en plena pubertad. Schlink, de profesión jurista, utiliza su novela como medio para cuestionar un pasado histórico reciente, presentando el comportamiento de los verdugos y de sus víctimas, el infierno de Auschwitz, y todo aquello aceptado como válido dentro de la Alemania de la primera mitad del siglo $\mathrm{xx}^{11}$. En efecto, y tomando palabras de Agamben (2000: 5), para que el ser humano pueda comprender todo lo acontecido en campos de exterminio como Auschwitz,

no solo falta [...] algo que se asemeje a un intento de comprensión global, sino el sentido y las razones del comportamiento de los verdugos y de las víctimas; muchas

${ }^{11}$ En este sentido, Schlink, como ya hiciera F. Schiller en sus novelas históricas, emplea la literatura y el hecho histórico para presentar cuestiones universales, tales como la justicia, la culpa y la relación entre responsabilidad-castigo, a modo de «envoltorio». 
veces, hasta sus mismas palabras siguen apareciendo como un enigma insondable, reforzando la opinión de los que quisieran que Auschwitz permaneciera incomprensible para siempre.

Sin embargo, en la propia obra se pone de manifiesto la aporía del conocimiento histórico, que es, en definitiva, la aporía de Auschwitz. Pues, a lo largo de la parte central de la novela, durante el desarrollo del juicio a Hanna, queda patente la no coincidencia entre hechos y verdad, entre comprobación y comprensión de los hechos; en definitiva, se trata de la inviabilidad de orden racional que nos impide comprender en toda su magnitud lo sucedido en el campo de exterminio, en el mismo sentido que Salmen Lewental, un integrante de un Sonderkommando, dejó plasmado su testimonio en algunas hojillas que enterró cerca del crematorio III, y que fueron encontradas diecisiete años después de la liberación de Auschwitz (Agamben 2000: 5):

Ningún ser humano puede imaginarse -escribe Lewental en su sencillo yiddish-los acontecimientos tan exactamente como se produjeron, y de hecho es inimaginable que nuestras experiencias puedan ser restituidas tan exactamente como ocurrieron... nosotros, un pequeño grupo de gente oscura que no dará demasiado que hacer a los historiadores.

En las páginas siguientes analizaremos los principales conceptos jurídicos tratados en la novela tomando como fuente principal el texto original alemán, que nos permitirá captar el sentido primigenio de la novela para el análisis que presentamos en este trabajo. La traducción al español, así como la versión cinematográfica de la novela, se emplearán como herramientas complementarias para abordar el análisis aquí propuesto. Para conseguir los objetivos enunciados, estableceremos una serie de ejes, todos ellos muy relacionados entre sí:

a) Jurisprudencia, justicia y validez.

b) Culpa criminal, culpa moral y culpa colectiva.

c) Proceso judicial, responsabilidad y castigo.

\subsection{JURISPRUDENCIA, JUSTICIA Y VALIDEZ}

La cuestión principal en torno a la jurisprudencia emana del hecho objetivo de que el Código Penal vigente en la época de los juicios ni siquiera contemplaba los crímenes que se habían cometido en los campos de concentración. El dilema, pues, quedaba de manifiesto ya en el inicio del seminario, planteado por Michael, y por la afirmación formulada por el profesor (Schlink 1995: 86):

Ich erinnere mich, daß im Seminar über das Verbot rückwirkender Bestrafung diskutiert wurde. Genügt es, daß der Paragraph, nach dem die KZ-Wächter und -Schergen verurteilt werden, schon zur Zeit ihrer Taten im Strafgesetzbuch stand, oder kommt es darauf an, wie er zur Zeit ihrer Taten verstanden und angewandt 
und daß er damals eben nicht auf sie bezogen wurde? Was ist das Recht? Was im Buch steht oder was in der Gesellschaft tatsächlich durchgesetzt und befolgt wird? Oder ist Recht, was, ob es im Buch steht oder nicht, durchgesetzt und befolgt werden müßte, wenn alles mit rechten Dingen zuginge? [...] «Sehen Sie sich die Angeklagten an - Sie werden keinen finden, der wirklich meint, er habe damals morden dürfen»"${ }^{12}$.

En este sentido, obsérvese que la traducción del término Recht no puede ser "Derecho, jurisprudencia», sino que el término más adecuado para la correcta recepción del sentido del texto alemán ha de ser «justicia». Del mismo modo, el término Buch ha de entenderse aquí como sinónimo de Strafgesetzbuch ("Código Penal»), como conjunto ordenado y sistematizado de las normas jurídicas punitivas que son aplicables en un Estado, y que definen y tipifican qué actos son considerados delitos, y cuáles son las penas aplicables a cada uno de ellos, en función del principio de proporcionalidad.

Esta cuestión de la validez de las leyes, y por tanto también de la justicia aplicada conforme a ellas, queda planteada también en la versión fílmica con la erudición del catedrático (The Reader) ${ }^{13}$ :

Catedrático: Nadie es culpable de nada únicamente por haber trabajado en Auschwitz. 8000 personas trabajaron en Auschwitz, de las que 19 fueron condenadas, y solo seis por asesinato, porque para que sea asesinato tienes que demostrar que hubo intención. Es la ley. La cuestión nunca puede ser: «¡estuvo mal?», sino: «¡fue legal?». Y eso no partiendo de las actuales leyes, no. Sino de las leyes de esa época. Alumno: ¿Pero eso no es...?

Catedrático: ¿… qué?

Alumno: ‘... limitado?

Catedrático: Oh, sí. La ley es limitada. Aunque por otro lado, sospecho que las personas que matan a otras personas tienden a saber que eso está mal.

Por tanto, la cuestión planteada tanto en la novela como en el film no es otra que esta: ¿qué validez tienen las leyes actuales para juzgar, hacer justicia y condenar por los crímenes cometidos, crímenes que ni siquiera están contemplados en dichas leyes? Para ello hemos de tener en cuenta que según el artículo 103.2 de la Constitución de la República Federal Alemana (Grundgesetz) un delito solo será punible si

12 «Recuerdo que en el seminario se discutió la prohibición de las penas retroactivas. ¿Basta con que el parágrafo según el cual se había condenado a los guardias de los campos de concentración y sus secuaces ya figurara en el código penal en el momento de sus actos criminales, o es importante cómo se entendió y se aplicó el código penal en aquel momento, sin en ocasiones hacer referencia a él? ¿Qué es el derecho? ¿Lo que está escrito en los códigos o lo que realmente se aplica y se cumple? ¿O es correcto aquello que, esté o no en el código penal, deber ser aplicado y cumplido si todo se hace correctamente? (...) "Mire a los acusados - no encontrará a nadie que realmente piense que en aquel momento tenía vía libre para asesinar”». Traducción de las autoras.

13 Utilizamos aquí la versión doblada al español de la película, a fin de emplear únicamente dos lenguas de trabajo en el análisis propuesto. 
está reflejado en el ordenamiento jurídico antes de que sea cometido ${ }^{14}$, lo que conlleva no solo un debate de tipo ético o moral, sino también jurídico. A esto hemos de añadir el hecho de que, como afirma Agamben (2000: 9): «La realidad es que, como los juristas saben perfectamente, el derecho no tiende en última instancia al establecimiento de la justicia. Tampoco al de la verdad. Tiende exclusivamente a la celebración del juicio, con independencia de la verdad o la justicia».

\subsection{CULPA CRIMINAL, CULPA MORAL Y CULPA COLECTIVA}

En la adaptación fílmica de la novela la primera lectura que el catedrático indica a los alumnos como tarea para el seminario es la de Karl Jaspers, sobre el problema de la culpa alemana ${ }^{15}$; Jaspers considera que la culpa puede contemplarse desde la perspectiva criminal, política, moral o metafísica. En Der Vorleser podemos distinguir dos tipos de culpa: la culpa criminal, aquella en la que el individuo ha de responder ante un tribunal por los delitos cometidos y recibir el castigo estipulado por el correspondiente ordenamiento jurídico; y la culpa moral, que nace de la cooperación del individuo con el Tercer Reich para llevar a cabo el genocidio. No obstante, y relacionado con ambos tipos de culpa, Schlink nos presenta mediante el desarrollo del juicio otra modalidad más: la culpa colectiva, aquella que no es exclusiva de los criminales nazis, sino de todo el pueblo alemán como corresponsable de aquellos terribles acontecimientos.

\subsubsection{Culpa criminal}

Es la culpa que con mayor claridad se nos expone en la segunda parte de la novela. Los chicos matriculados en el seminario, y especialmente Michael, tenían clara la necesidad de que hubiera condenas por los crímenes cometidos (Schlink 1995: 87):

Daß verurteilt werden müsse, stand für uns fest. Ebenso fest stand für uns, daß es nur vordergründig um die Verurteilung dieses oder jenes KZ-Wächters und Schergen ging. Die Generation, die sich der Wächter und Schergen bedient oder sie nicht gehindert oder sie nicht wenigstens ausgestoßen hatte, als sie nach 1945

${ }^{14}$ Los artículos 92-104 de la Constitución alemana regulan la jurisprudencia (Rechtsprechung). En concreto, el artículo 103.2. reza así: «Eine Tat kann nur bestraft werden, wenn die Strafbarkeit gesetzlich bestimmt war, bevor die Tat begangen wurde» ("Un delito solo puede ser condenado si está estipulado legalmente en el código penal, antes de que dicho delito sea cometido»). Traducción de las autoras.

15 Vid. Jaspers (1946), quien no aboga por una culpa colectiva, pero sí por la responsabilidad de todos los ciudadanos. 
hätte ausgestoßen können, stand vor Gericht, und wir verurteilten sie in einem Verfahren der Aufarbeitung und Aufklärung zu Scham ${ }^{16}$.

A esta culpa y este sentimiento de vergüenza que experimenta esa segunda generación, a la que Michael hace referencia con total claridad en la narración (Schlink 1995: 87), también alude el autor como jurista en uno de sus ensayos (2007: 12 y 88):

Juristisch gibt es keinen Schluß von der Schuld eines Menschen auf die Schuld eines anderen; es gibt Schuldübertragungen weder in der Horizontalten, unter den Angehörigen einer Generation, noch in der Vertikalten, von der einen Generation auf die nächste.

[...]

Daß die Täter der dritten Reichs nicht ausgestoßen, nicht verfolgt und verurteilt, sondern toleriert, respektiert, in ihren Positionen belassen und bei ihren Karrieren gefördert, als Eltern und Lehrer akzeptiert wurden, hat die Generation der Täter und die ihrer Kinder in die Verbrechen und Schuld des Dritten Reichs verstrickt ${ }^{17}$.

Es la culpa criminal precisamente la que alcanza a Hanna, y por ello es llevada ante el tribunal. En este sentido, el personaje de Hanna representa a aquellos que también fueron alcanzados por su pasado nazi cuando ya habían transcurrido muchos ańos ${ }^{18}$. Hanna es una alemana. Una alemana que vivió durante el nacionalsocialismo y que sirvió a la Alemania nazi; hasta el juicio, e incluso tras la condena, Hanna entiende que cumplía con su deber (Schlink 1995: 107): "Ich habe... ich meine... Was hätten Sie denn gemacht?” Das war von Hanna als ernste Frage gemeint. Sie wußte nicht, was si hätte anders machen sollen, anders machen können, und wollte daher vom Vorsitzenden, der alles zu wissen schien, hören, was er gemacht hätte» ${ }^{19}$.

16 "Que hacían falta condenas lo teníamos claro». Tan claro como que la condena de los guardianes y los esbirros de este o aquel campo de concentración no era más que un primer paso. La generación que había servido al guardián o al esbirro o que no los había obstaculizado, o que ni siquiera los había repudiado tras 1945 , cuando podía haberlo hecho, era la generación que también estaba ante un tribunal, y nosotros, con nuestro proceso de revisión y esclarecimiento queríamos condenarla a la vergüenza». Traducción de las autoras.

17 «Jurídicamente no existe la expiación de la culpa de una persona en la de otra, sino que la culpa pasa tanto en horizontal, entre los integrantes de una generación, como en vertical, de una generación a la siguiente. [...] El hecho de que los asesinos del Tercer Reich no hayan sido repudiados, perseguidos ni juzgados, sino tolerados, respetados, reestablecidos en su posición social y promocionados en sus carreras profesionales, aceptados como padres y profesores, ha implicado a la generación de criminales y de sus hijos en el crimen y la culpa del Tercer Reich». Traducción de las autoras.

${ }^{18}$ Es representativo el caso de Heinrich Lübke, que tuvo que dimitir como Bundespräsident por la falta de apoyo político y social a raíz de su pasado nacionalsocialista.

19 “"Yo... quiero decir... ¿Qué habría hecho usted entonces?”. Esa fue la pregunta más seria que formuló Hanna. No sabía qué otra cosa debía haber hecho, qué otra cosa podría haber hecho, y por eso quería saber, y oír del juez, qué habría hecho él». 
La culpa criminal, pues, está íntimamente ligada con el concepto de responsabilidad. Se trata de una culpa genuinamente jurídica, no ética, y como tal, un daño solo es imputable a este tipo de culpa. De este modo, podemos entender la argumentación de la defensa de Eichmann durante el proceso que juzgó sus crímenes en Jerusalén, al afirmar que se sentía culpable ante Dios, pero no ante la ley. Y por tanto, esa culpabilidad ante Dios no era jurídicamente perseguible. Dado que obedecía a su Führer, afirmó Eichmann, era ese Führerprinzip el que regía todo su comportamiento, por lo que estaba exento de toda responsabilidad ${ }^{20}$.

\subsubsection{Culpa moral}

El comportamiento criminal de Hanna se presenta en la novela magistralmente envuelto en un halo de analfabetismo, lo que le impide tener sentido crítico y, por tanto, discernir el bien del mal dentro del sistema nacionalsocialista. Solo cuando Hanna aprende a leer y a través de la literatura es consciente de las atrocidades que cometió durante el Tercer Reich, solo cuando hay consciencia a través de la formación aparece la conciencia. Por ello, sabiéndose incapaz de separarse de la culpa que siente de forma personal, íntima, individual, pero que no puede desligar de esa otra culpa colectiva de su pueblo, decide terminar con su vida.

Esta culpa moral, heredada del nacionalsocialismo por los Nachgeborenen, es la que causa vergüenza y estupefacción (Schlink 1995: 99s.):

Was sollte und soll meine Generation der Nachlebenden eigentlich mit den Informationen über die Furchtbarkeiten der Vernichtung der Juden anfangen? Wir sollen nicht meinen, begreifen zu können, was unbegreiflich ist, dürfen nicht vergleichen, was unvergleichlich ist, dürfen nicht nachfragen, weil der Nachfragende die Furchtbarkeiten, auch wenn er sie nicht in Frage stellt, doch zum Gegenstand der Kommunikation macht und nicht als etwas nimmt, vor dem er nur in Entsetzen, Scham und Schuld verstummen kann. Sollen wir nur in Entsetzen, Scham und Schuld verstummen? Zu welchem Ende? Nicht daß sich der Aufarbeitungs- und Aufklärungseifer, mit dem ich am Seminar teilgenommen hatte, in der Verhandlung einfach verloren hätte. Aber daß eineige wenige verurteilt und bestraft und daß wir, die nachfolgende Generation, in Entsetzen, Scham und Schuld vertummen würden - das sollte es sein?21

20 Esta tesis del cumplimiento del deber y la obediencia a Hitler, junto al concepto de «banalidad del mal», fue puesta de manifiesto por Arendt (1963).

21 «¿Qué debió y debe realmente acometer mi generación, la segunda generación, con la información que tiene sobre los horrores del exterminio de los judíos? ¿Puede acaso pretender comprender lo incomprensible, tiene derecho a comparar lo incomparable o a cuestionar nada, si aquel que cuestione algo así, aun cuando no dude de aquellos horrores, lo convierte en objeto de comunicación y lo asume como algo ante lo cual lo único que cabe es enmudecer, lleno de espanto, vergüenza y culpa? ¿Y con qué fin? No es que se hubiera esfumado el entusiasmo por revisar y esclarecer con el que había comenzado el seminario y asistido al juicio. Pero... ¿acaso tenía que ser así? ¿Unos 


\subsubsection{Culpa colectiva}

Esta misma culpa moral es la que está presente en la obra como culpa colectiva, exenta de consecuencias legales o jurídicas, en el sentido en el que lo expone Giordano (278):

Die Kollektivschuld der Deutschen unter Hitler hatte für mich nie auch nur die geringste justitielle Bedeutung gehabt, sondern stets eine moralische. Sie hatte in meinen Augen nie etwas zu tun mit Gerichten, Gefängnissen, Zuchthauszellen - Kollektivschuld ist nist justitiabel. Für mich sollte das Eingeständnis der Kollektivschuld nie etwas anderes als Erlösung herbeiführen, ich habe es nie in einem anderen Sinne gesehen als einen Akt innerer Befreiung $[. . .]^{22}$.

No todos consideraron siempre la existencia de la culpa colectiva. Así, el sociólogo Eugen Kogon (1946), prisionero durante toda la guerra del campo de concentración de Buchenwald, rechaza la tesis de una Kollektivschuld y culpa exclusivamente a los criminales nazis, si bien es cierto que argumenta que aunque el ciudadano de a pie desconocía el detalle del horror de los campos de concentración, ningún alemán era ajeno a la existencia de estos campos. Frente a esta postura está la de Victor Klemperer (1995), quien en sus diarios sí alude a finales de los años 90 a una culpa colectiva.

Llegados a este punto cabe concluir que el discurso jurídico sirve como envoltorio para una cuestión mucho más compleja: la superación del pasado y de la culpa, que va unida irremediablemente a dicho pasado. En este sentido, conviene recordar lo que Schlink, como jurista, determina en torno al concepto de culpa (2007: 7):

Schuld kann nicht nur einzelne Menschen betreffen, sondern ganze Generationen, nicht nur einzelne Taten, sondern ganze Abschitte der Geschichte. Die Abschnitte werden Vergangenheit und verdunkeln gleichwohl die Gegenwart - sie werden Vergangenheitsschud ${ }^{23}$.

pocos juzgados y condenados, y nosotros, la generación siguiente, enmudecida por el espanto, la vergüenza y la culpa?». Traducción de las autoras.

22 «La culpa colectiva de los alemanes bajo el régimen de Hitler no había tenido para mí el más mínimo sentido judicial, sino únicamente un sentido moral. A mis ojos nunca tuvo nada que ver con juzgados, prisiones o celdas: la culpa colectiva no puede ser ajusticiada. Para mí el reconocimiento de la culpa colectiva no es otra cosa que una liberación, nunca la he visto como un acto distinto a la liberación interior [...]». Traducción de las autoras.

23 «La culpa no puede alcanzar únicamente a una persona, sino a generaciones enteras, no es exclusivo de hechos aislados, sino de etapas completas de la Historia. Las etapas se convierten en pasado y se tornan tan oscuras como el presente: se convierten en culpas del pasado». Traducción de las autoras. 
La generación de Michael -en definitiva, la generación del propio Schlinkvivió muy de cerca los grandes enjuiciamientos de la posguerra; la mayoría de ellos tuvieron lugar durante la década de los años 60 del pasado siglo. Uno de los juicios que conmocionaron al mundo fue el proceso a Adolf Eichmann en Jerusalén entre 1961 y 1962: era la primera vez que se conocían todos los detalles del asesinato masivo y sistematizado de judíos ante una corte. El proceso judicial que aquí se presenta constituye una clara alusión al denominado «Proceso de Auschwitz», celebrado en Fráncfort del Meno desde 1963 hasta 1965 contra veintidós funcionarios del campo de concentración; este juicio supuso un cambio de paradigma en la persecución de los crímenes nazis: «Die Gerichtsverhandlung war in einer anderer Stadt, mit dem Auto eine knappe Stunde entfernt» (Schlink 1995: 90)24. No obstante, el hecho de que fueran cinco las acusadas en el proceso judicial de la novela nos recuerda a otro juicio, el celebrado en Düsseldorf desde 1974 hasta 1981 contra dieciséis funcionarios del campo de concentración de Majdanek, entre los que se encontraban cinco mujeres. Michael, no obstante, afirma que no se trataba de un juicio relevante: «Es war nicht der erste KZ-Prozeß und keiner der großen» (Schlink 1995: 86) ${ }^{25}$.

Ya centrándonos en el juicio que se presenta en la obra, la descripción que hace Michael de la corte que juzgará el caso es pormenorizada (Schlink 1995: 90s.):

Der Gerichtsverhandlung hatte am Montag begonnen. Die ersten drei Verhandlungstage waren mit Befanggenheitsanträgen der Verteidiger vergangen. [...] Der Saal, in dem das Schwurgericht tagte, hatte links eine Reihe großer Fenster, deren Milchglas den Blick nach draußen verwehrte, aber viel Licht herienließ. Von den Fenster saßen die Staatasanwälte, an hellen Frühling- und Sommertagen nur in dem Umrissen erkenbar. Das Gericht, drei Richter in schwarzen Roben und sechs Schöffen, saß an der Stirn des Saals, und rechts war die Bank der Angeklagten und Verteidiger, wegen der großen Zahl mit Tischen und Stühlen bis in die Mitte des Saals vor die Reihen des Publikums verlängert. Einige Angeklagte und Verteidiger saßen mit dem Rücken zu uns. Hanna saß mit dem Rücken zu uns ${ }^{26}$.

${ }^{24}$ «El juicio se celebraba en otra ciudad, apenas a una hora de camino en coche». Traducción de las autoras. En la versión fílmica, no obstante, el grupo de estudiantes, junto con el profesor, se desplaza en tren hacia la ciudad en la que tiene lugar el juicio.

25 «No era el primer juicio sobre campos de exterminio, y tampoco era ninguno de los relevantes». Traducción de las autoras.

26 «El juicio había comenzado el lunes. En las tres primeras sesiones se habían visto las recusaciones de los abogados defensores [...] la sala en la que tenían lugar las vistas tenía a su izquierda una hilera de ventanales, cuya silueta solo era perceptible en los días claros de primavera y verano. El tribunal, formado por tres jueces con togas negras y seis jurados, estaba sentado al frente de la sala, y a la derecha se encontraba el banquillo de las acusadas y los abogados defensores, que debido a su elevado número hubieron de ser ampliados con sillas y mesas hasta la mitad de la sala, justo delante de las filas de público. Algunas de las acusadas y sus abogados estaban sentados dándonos la espalda. También Hanna». Traducción de las autoras. 
Este capítulo, el tercero de la segunda parte de la novela, contiene conceptos jurídicos y judiciales importantes:

a) Gerichtsverhandlung: juicio, vista oral. El juicio forma parte de un procedimiento de carácter jurídico más amplio, denominado proceso. En este sentido, cabe señalar la diferenciación entre el término KZ-Prozeß (Schlink 1995: 89) y Gerichtsverhandlung (Schlink 1995: 90) que se establece en la novela: el primero de ellos hace referencia no únicamente a la vista oral, sino a todo el procedimiento penal hasta llegar a la condena de los acusados, y a la ejecución de las sentencias, y el segundo hace referencia únicamente a la vista oral en la que las partes procesales exponen sus alegatos.

b) Verhandlungstage (Schlink 1995: 90): se refiere a cada sesión en la cual se divide el juicio. Es, pues, cada jornada de juicio oral que se desarrolla. En este sentido, nos parece apropiado como equivalencia el término «sesión $»^{27}$.

c) Befangenheitsanträgen (Schlink 1995: 90): como sinónimo de Ablehnungsgesuch, el término hace referencia a la solicitud de recusación por parcialidad, que ha de ser presentada por el abogado defensor. Tal vez esta trama de la recusación tenga por objetivo recordar al lector que en algunos procesos los abogados defensores tenían afinidad con los movimientos nazis y neonazis, de ahí que el abogado de Hanna fuera «der einzige junge Verteidigter, die anderen waren alt, einige, wie sich bald zeigte, alte Nazis» (Schlink 1995: 92) ${ }^{28}$.

d) Verteidigter (Schlink 1995: 90): abogado defensor. El derecho alemán distingue entre Anwalt der Gegenpartei («abogado de la contraparte»), Korrespondenzanwalt («abogado corresponsal»), Pflichtverteidiger («abogado de oficio»), Landesanwalt («abogado provincial») y Beweisanwalt («abogado de pruebas»).

e) Angeklagten (Schlink 1995: 90): como sinónimo de Angeschuldigte, los acusados son aquellos a los que se juzga y que han de comparecer en la vista oral.

f) Gericht: este término hace alusión a dos conceptos: por un lado, el edificio en el que tiene lugar la vista oral, esto es, el juzgado o el Palacio de Justicia: «Das Gericht war ein Bau der Jahrhundertwende, aber ohne dem Pompo und die Düsternis die damalige Gerichtsbauten oft zeigen» (1995: 90) ${ }^{29}$; por otro, la corte, el tribunal que ha de juzgar a los acusados: «Das Gericht, drei Richter in schwarzen Roben und sechs Schöffen [...]» (Schlink 1995: 91) ${ }^{30}$.

27 Parra (1997: 90), no obstante, adopta una traducción literal y emplea el término «días»: «Durante los tres primeros días se habían visto...». Estimamos que una traducción literal resta contenido jurídico al discurso, de ahí que en la traducción efectuada por las autoras se haya empleado el término «sesiones». Vid. nota anterior.

28 «el único abogado defensor joven, todos los demás eran viejos; algunos, como pronto se puso de manifiesto, antiguos nazis». Traducción de las autoras.

29 «El Palacio de Justicia era un edificio de finales del siglo pasado, pero sin la pompa y el aire siniestro que solían mostrar los juzgados de aquel entonces». Traducción de las autoras.

${ }^{30} \mathrm{Vid}$. nota 18. 
g) Schwurgericht (Schlink 1995: 90): también denominado Geschworenengericht, corresponde a lo que en el estamento judicial español es un tribunal del jurado, si bien su composición es distinta. En el caso alemán, está compuesto por tres jueces de carrera (Berufsrichter) ${ }^{31}$ y dos jurados (Schöffen) por cada uno de ellos.

h) Vorsitzende: es el magistrado que preside el tribunal ${ }^{32}$; es el de mayor categoría y rango de los tres jueces que lo componen. Los otros jueces reciben la denominación de Beisitzender (Schlink 1995: 92):

Er erreichte zwar, daß der Vorsitzende irritiert schaute und die Frage, warum Hanna zur SS gegangen war, nicht weiter verfolgte. [...]. Daß ein Beisitzender Hanna fragte, was für eine Arbeit sie bei der SS erwartet habe, und daß Hanna erklärte, die SS habe bei Siemens, aber auch in anderen Betrieben Frauen für den Einsatz im Wachdienst geworben, dafür habe sie sich gemeldet un dafür sei sie eingestellt worden änderte am negativen Eindruck nichts mehr ${ }^{33}$.

i) Haftrichter / Haftsbefehl: junto a los jueces de la vista oral, y como acto jurídico y judicial previo que es la instrucción del caso, también en la obra se hace referencia al juez instructor y a la instrucción (Schlink 1995: 94):

«Sie meinen also, der Haftrichter hat dem Umstand, daß die Angeklagte auf kein Schreiben und keine Ladung reagiert hat, nicht vor der Polizei, nicht vor dem Staatsanwalt und nicht vor dem Richter erschienen ist, eine falsche Bedeutung zugemessen? Sie wollen einen Antrag auf Aufhebung des Haftsbefehls stellen? ${ }^{34}$

j) Staatsanwalt: como parte procesal, también aparece la figura del fiscal, parte acusadora del proceso. Cabe señalar que en el filme hay una alusión clara al

31 En la novela aparece el término genérico Richter.

32 Estimamos que el término «presidente», tal y como aparece en la traducción de Parra (1997: 92), resta significado jurídico al texto, y en ocasiones incluso induce a error, pues a veces se emplea este término, y otras el término «juez» para referirse al presidente del tribunal (Parra 1997: 92s.). La equivalencia de esta figura en el sistema judicial español es el magistrado-presidente. De este modo, se distinguiría con claridad entre el magistrado -quien preside el tribunal-y los jueces -aquellos otros que lo acompañan-, al tiempo que se dotaría al discurso del contenido jurídico y judicial que requiere la escena.

33 «Consiguió, no obstante, que el juez pareciera algo ofuscado y que no continuara formulando la pregunta de por qué Hanna había ingresado en las SS [...] Que otro de los jueces preguntara a Hanna qué clase de trabajo esperaba encontrar en las SS, y que Hanna declarara que las SS habían ido a Siemens y a otras compañías a reclutar a mujeres para que trabajaran como guardianas, y por eso se había alistado y esa tarea era la que le habían asignado, lo que no disipó ya la impresión negativa que tenía el tribunal sobre ella». Traducción de las autoras.

34 «QQuiere decir entonces que el juez instructor no debería haber tenido en cuenta que la acusada no ha respondido a ninguna de las citaciones que se le han enviado por escrito, ni ha comparecido ante la policía, ante el fiscal o ante el juez de primera instancia para no incurrir en error? ¿¿Desea presentar una instancia para el levantamiento de la prisión incondicional?». Traducción de las autoras. 
procedimiento judicial, cuando el magistrado presidente aclara a la audiencia cómo se desarrollarán las sesiones (The Reader):

Magistrado: El tribunal abre la sesión. Por favor siéntense. Lo primero que hará este tribunal es escuchar las alegaciones de cada uno de los abogados defensores. Supongo que se basarán en que no hay motivos para que sus defendidas permanezcan en la cárcel hasta saber el veredicto final, así que estudiaremos cada caso en particular.

Tras un interrogatorio previo, se procede a la lectura de los cargos a las acusadas. Se trata, como se indica en la obra, de una parrafada llena de tecnicismos y fórmulas jurídicas, como lo indican los términos Verlesung ("lectura de cargos»), Angeklagte ("acusada»), Tatbestand («hecho, delito»), rechtswidrig («ilegal»), schuldhaft ("culpable») o Paragraphen ("artículos»):

Die Verlesung dauerte eineinhalb Tage - eineinhalb Tage Konjunktiv. Die Angeklagte zu eins habe..., sie habe ferner..., weiter habe sie..., dadurch habe sie den Tatbestand des Paragraphen soundsoviel erfüllt, ferner habe sie diesen Tatbestand un jenen Tatbestand..., sie habe auch rechtswidrig und schuldhaft gehandelt. Hanna war die Angeklagte zu vier (Schlink 1995: 101) ${ }^{35}$.

Los puntos álgidos de toda la acción judicial presentada en la novela son, por su parte, las declaraciones de Hanna; dichas declaraciones se centran en las dos acusaciones principales (Schlink 1995: 102s.):

Der eine Hauptanklagepunkt galt den Selektionen im Lager. Jeden Monat wurden aus Auschwitz rund sechzig neue Frauen geschickt und waren ebenso viele nach Auschwitz zurückzuschicken, abzüglich derer, die in der Zwischenzeit gestorben waren. Allen war klar, daß die Frauen in Auschwitz umgebracht wurden; (...) Der andere Hauptanklagepunkt galt der Bombennacht, mit der alles zu Ende ging ${ }^{36}$.

Con respecto a ambas acusaciones, la relativa al proceso de selección es la que muestra mayor intensidad emocional, ética y moral, tanto en la obra como en la película. Mientras que la novela nos describe, a través de los ojos de Michael, algunas de las partes de la declaración de Hanna, el film centra su atención en la guardiana, y le concede todo el protagonismo de la escena (The Reader):

35 «La lectura de cargos duró un día y medio. Un día y medio de condicionales. La acusada número uno cometió... después... además...; con ello infringió el artículo tal, además incurrió en esto y aquello... cometió igualmente aquel acto punible. Hanna era la acusada número cuatro». Traducción de las autoras.

36 «El primer punto principal de la acusación hacía referencia a la selección que se efectuaba en el campo de concentración. Cada mes llegaban unas sesenta mujeres procedentes de Auschwitz, y otras tantas eran devueltas al campo de exterminio, excepto aquellas que habían muerto durante su estancia en el campo de concentración. Todos sabían que las mujeres devueltas a Auschwitz eran asesinadas [...]. El otro punto principal de la acusación hacía referencia a la noche del bombardeo que acabó con todo». Traducción de las autoras. 
Magistrado: Señorita Schmitz, ¿reconoce este libro?

Hanna: Sí.

Magistrado: Algunas partes ya han sido leídas en voz alta en la sala. Lo encontró una superviviente, una prisionera que sobrevivió, Ilana Matter; ella estuvo en el campo de niña, ¿̇no es así? ¿Estaba con su madre?

Hanna: Sí.

Magistrado: En el libro, ella describe un proceso de selección, después de trabajar durante un mes seleccionaban a sesenta presas. Las elegían para enviarlas desde el campo satélite a Auschwitz. Es correcto, ¿verdad?

Hanna: Sí, es correcto.

Magistrado: Por el momento cada una de sus compañeras acusadas ha negado haber tomado parte en dicho proceso. Bien, ahora se lo pregunto a usted. ¿Tomó parte en él?

Hanna: Sí.

Magistrado: ¿O sea que usted ayudó a hacer la selección?

Hanna: Sí.

Magistrado: ¿Lo admite?

(Hanna asiente con la cabeza)

Magistrado: Bien, dígame, ¿cómo funcionaba dicha selección?

Hanna: Éramos seis guardianas, así que decidimos que cada una eligiera a diez personas. Lo hacíamos así cada mes. Todas elegíamos a diez.

Magistrado: ¿Afirma que todas las acusadas tomaron parte en el proceso?

Hanna: Todas lo hicimos (seńalando y mirando hacia el resto de las acusadas).

Magistrado: ¿Aunque ellas lo nieguen? Decir «nosotras» es más fácil que decir «yo sola», ¿ ¿no es así, señorita Schmitz?

Hanna: Eh...

Magistrado: ¿Acaso no se daba cuenta de que enviaba a esas mujeres a la muerte?

Hanna: Sí pero... llegaban otras, llegaban mujeres constantemente, así que las que estaban en el campo tenían que dejar sitio a las que venían.

Magistrado: Uhm... Creo que no lo ha entendido.

Hanna: No podíamos quedarnos con todas. ¡No había sitio!

Magistrado: No. Lo que le estoy diciendo se lo diré de otro modo: para tener sitio elegían entre ellas y decían: «a ti, a ti y a ti os enviaremos allí para que os maten». Hanna: Pero... ¿qué hubiera hecho usted?

(El magistrado no responde)

Hanna: Según esto, ¿tampoco debí trabajar en Siemens?

(Nuevamente silencio del magistrado)

Del mismo modo, Daldry también concede a las dos únicas testigos de cuanto sucedió el día de autos el merecido protagonismo de las víctimas. Así, mientras que en la versión fílmica hija -a la que únicamente en la película se le dota de nombre propio- y madre declaran relatando los acontecimientos, en la novela únicamente lo hace la hija, pues la madre permanece en Israel (Schlink 1995: 102): «Zur Vernehmung der Mutter fuhrern Gericht, Staatsanwälte und Verteidiger nach 
Israel -der einzige Abschnitt der Verhandlung den ich nicht miterlebt habe ${ }^{37}$. Sobre Hanna, la gran pantalla nos ofrece la declaración que hace Ilena en el estrado, que en la novela aparece como consecuencia de un recuerdo espontáneo que brota en la mente de la hija a medida que oye las declaraciones de la guardiana (The Reader):

Ilena: Tenía sus favoritas. La mayoría eran jóvenes. Todas lo comentábamos. Les daba comida y un lugar para dormir. Por la noche les pedía que la acompańaran y todas creíamos... bueno ya puede imaginarse lo que creíamos, pero descubrimos que obligaba a esas mujeres a leerle en voz alta. Ellas le leían. Al principio pensamos que esa guardiana era más... más sensible, más humana; era amable; a menudo elegía a las débiles, a las enfermas; las seleccionaba y parecía que las protegía. Pero al final las enviaba a la muerte. ¿Era eso amable?

Llegados a este punto cabe reflexionar sobre la importancia capital que tanto en la novela como en la versión fílmica tienen las testigos, dado que suponen una nueva confluencia entre el hecho jurídico y el hecho histórico. Así, desde el punto de vista jurídico, "testigo», del latín testis, es aquel tercero que se sitúa en un proceso o litigio entre ambas partes contendientes. Pero aquí nuevamente se juega con esa dualidad ético-jurídica, dado que vemos a una testigo no solo en el sentido estricto de la jurisprudencia, sino también con la acepción latina de superstes, esto es, aquella persona que ha vivido $-\mathrm{y}$ sobrevivido- a una horrenda realidad, y que está en condiciones de ofrecer un testimonio sobre ella.

El segundo interrogatorio, sobre el informe redactado tras lo acontecido durante el bombardeo de la iglesia y la muerte de las prisioneras presas del fuego, culminará con la confesión de Hanna, quien no había redactado el mencionado informe, pero que desea evitar, a toda costa, la vergüenza de dar a conocer al mundo que es analfabeta. Hemos de matizar, sin embargo, que dicha confesión conlleva una responsabilidad de tipo genuinamente jurídico, lo que supondrá de forma irremediable la imputabilidad del daño causado y la correspondiente condena. En este punto se hace referencia, igualmente, a la fase probatoria del juicio, y así, se alude a la prueba caligráfica como medio para determinar si realmente fue Hanna quien redactó el informe (Schlink 124): «Ein Staatsanwalt schlug vor, einen Sachverständigen die Schrift des Berichts und die Schrift der Angeklagten Schmitz miteinander vergleichen zu Lassen ${ }^{38}$.

Finalmente, y tras la confesión de la guardiana, el caso queda visto para sentencia y a finales de junio el tribunal emite su veredicto. Nuevamente encontramos expresiones y términos propios del lenguaje jurídico: das Urteil verkünden («dictar sentencia»), lebensläglich bekommen ("ser condenado a cadena perpetua»), Frei-

37 «El tribunal, los fiscales y los abogados defensores se desplazaron hasta Israel para tomar declaración a la madre. Fue la única parte del juicio que no presencié». Traducción de las autoras.

38 «Un fiscal propuso mandar a realizar un estudio grafológico para comparar la letra del informe y la de la acusada Schmitz». Traducción de las autoras. 
heitsstrafen ("penas privativas de libertad»), Begründung des Urteils ("fundamentos de derecho", "considerandos de la sentencia»), y Verlesung ("lectura [de la sentencia]»):

Ende Juni wurde das Urteil verkündet. Hanna bekam lebensläglich. Die anderen bekamen zeitliche Freiheitsstrafen. [...] Sie fanden das Verfahren, das Urteil und auch sich, die sie zur Verkündung des Urteils gekommen waren, von Hanna verhöhnt. [...] Bei der Verlesung der Begründung des Urteils saß sie. [...] Die Verlesung dauerte mehrere Stunden (Schlink 1995: 156s.) ${ }^{39}$.

\section{CONCLUSIONES}

A tenor de lo expuesto en las páginas precedentes podemos afirmar que, desde el punto de vista jurídico, la obra plantea al lector cuestiones que lo hacen reflexionar y, al mismo tiempo, lo obligan a tomar decisiones, todas ellas relacionadas no solo con la legalidad y el castigo correcto y proporcionado de los crímenes, sino también con la moralidad y la compensación a las víctimas. Desde el punto de vista literario, la función de la novela de Schlink se asemeja a las que en el periodo Clásico alemán desempeñaban las novelas históricas de F. Schiller: el hecho histórico y la relación amorosa constituyen el marco que sirve para «envolver» las cuestiones morales y jurídicas que se plantean en la obra, suscitando en el lector la reflexión sobre lo planteado en la obra. En este sentido, y con respecto a la justicia, Der Vorleser llega a suscitar en el lector el planteamiento de si existió realmente justicia en los procesos contra los criminales nazis, y, de ser así, si la justicia aplicada fue realmente válida. Para ello, Schlink juega con los conceptos jurídicos y la realidad histórica, y su novela sirve al autor para poner de manifiesto que los juicios contra los crímenes de guerra, sin lugar a dudas necesarios, fueron insuficientes desde el punto de vista jurídico, lo que equivaldría a poner en tela de juicio al Derecho mismo.

Por otra parte, la novela presenta el cuestionamiento del papel que desempeñan la responsabilidad y la culpa, ya sea individual o colectiva, en la definición de la identidad de un pueblo que, como el alemán, ha sido capaz de cometer crímenes atroces, amparados, legitimados y autorizados por el ordenamiento jurídico vigente en aquella época. En este sentido, Schlink pretende diferenciar en su novela las categorías éticas de las categorías jurídicas, a veces confundidas, especialmente en torno a todo lo que sucedió en Auschwitz. De este modo, la admisión tácita de una culpa moral por parte de Hanna queda separada claramente de la culpa jurídica, pues la condena a prisión no puede, en modo alguno, expiar la culpa moral. Esta diferenciación queda netamente presentada con el suicidio de Hanna: la guar-

39 «La sentencia se pronunció a finales de junio. Hanna fue condenada a cadena perpetua. Las otras quedaron en libertad una vez cumplidas sus condenas. [...] Consideraron que Hanna se había burlado del proceso, de la sentencia y hasta de aquellos que habían acudido a oír la sentencia. [...] Durante la lectura de los considerandos, Hanna permaneció sentada [...]. La lectura duró varias horas». Traducción de las autoras. 
diana muere no para pagar su responsabilidad jurídica, sino para expiar moralmente la culpa que aún sentía a pesar de estar, a los ojos de la humanidad, pagando por los delitos cometidos.

Cuestión aparte es la superación del pasado; la novela plantea, a través del protagonista, si ciertamente el relevo generacional puede ofrecer la posibilidad de superar el pasado nacionalsocialista; es más, si una segunda e incluso una tercera generación ofrecerán la distancia suficiente para recordar el pasado nazi sin sentirse definido por él y, con ello, cerrar ese círculo maldito. Más allá de este relevo, y desde el punto de vista jurídico, la novela plantea si el Derecho, por sí mismo, puede afrontar el pasado y superar esa Vergangenheitsschuld («culpa del pasado»), o si, como afirma Schlink (2007: 80), «aquello que ha sucedido no puede superarse ${ }^{40}$. En este sentido, estimamos que el autor, nuevamente sirviéndose de sus conocimientos jurídicos, pone de manifiesto algo singular: y es que los juicios celebrados, a pesar de su manifiesta insuficiencia, contribuyeron a difundir que el problema había sido superado tras la ejecución de las respectivas condenas. Esta pseudosuperación a la que alude toda la novela tal vez fuese válida para la generación que vivió la guerra y las atrocidades en ella cometidas, no siendo así para esa segunda generación que contempla con estupor la imposibilidad del sistema jurídico de juzgar los crímenes cometidos y, con ello, de superar el pasado. Será muchos años después, con la muerte de Hanna, cuando Michael entienda que solo con el perdón de la culpa moral es posible superar el pasado.

Este es, a nuestro entender, el verdadero valor de Der Vorleser: más allá de presentarnos una historia de amor, sexo, culpa y castigo, Hanna y Michael tienen como misión fundamental portar el peso de sus respectivas generaciones para mostrarlas al lector: la reconstrucción de Alemania que aparece descrita en la obra puede ser considerada una alegoría de la «reconstrucción» del pueblo alemán. Por ello, ambos personajes no pierden nunca su dimensión humana, moral y psicológica.

Tal vez la clave no sea una Vergangenheitsbewältigung («superación del pasado»), sino, como el propio Michael Berg relata, una Aufbearbeitung der Vergangenheit, esto es, una revisión del pasado. Solo llevando a cabo dicha revisión, entendiendo las atrocidades cometidas, y el peligro latente de que una sociedad que no revisa su pasado puede caer en los mismos errores, lograremos superar el pasado más oscuro y execrable de la historia de Alemania y de Europa. Un pasado que, como Alemania, necesita de una reconstrucción.

Y, retomando las palabras del viejo profesor de la versión cinematográfica, el discurso jurídico es el envoltorio que presenta lo acontecido en el pasado, pero sobre todo, nos hace ser conscientes de que las sociedades «creen regirse por algo llamado moralidad, pero no es así. Se rigen por algo llamado ley». Sirve, pues, para

40 «Was geschehen ist, kann nicht bewältigt werden. Es kann erinnert, vergessen oder verdrängt werden. [...]. Es kann wiederholt werden, bewußt oder unbewußt. [...]. Aber was geschehen ist, ist geschehen. Die Vergangenheit ist unreichbar und unveränderbar» (Schlink 2007: 80). «Lo que ha sucedido, no puede superarse. Se puede recordar, olvidar o reprimir. [...] Se puede repetir, consciente o inconscientemente. [...] Pero lo que ha sucedido, ha sucedido». Traducción de las autoras. 
transmitir la advertencia que nos hace la historia, y condenar la banalidad del mal y la barbarie humana. En palabras del joven Michael, y como dice a voz en grito en el film: «Estamos intentando comprender!».

RECiBido: mayo de 2019; ACEPTADO: junio de 2020 


\section{BIBLIOGRAFÍA}

Agamben, Giorgio (2000): Lo que queda de Auschwitz. El archivo y el testigo HOMO SAGER III, Valencia: Pretextos.

Arendt, Hannah (2005): Eichmann in Jerusalem, Barcelona: DeBOLSILLO.

Auer, Stefan (2014): «Holocaust als Fiktion. Von Andrezej Wajda bis Quentin Tarantino», Osteuropa 64: 103-114.

Bonilla, Daniel (2005): «Justicia y derecho: el engaño y la justicia de Selb», Precedente. Revista Jurídica: 99-111.

Castillo, Pilar (2016): El lenguaje de especialidad en la literatura: Der Vorleser de Bernhard Schlink y su traducción al español, tesis doctoral, Córdoba: UCOPress.

Deissner, David y Thomas Lindemann (2007): «Ist ,Der Vorleser` ein großer Roman?», Die Welt, Oct. 2007: 15 abril 2019. <https://www.welt.de/kultur/article1241861/Ist-Der-Vorleserein-grosser-Roman.html>.

Dreike, Beate M. (2005): «Was wäre denn Gerechtigkeit? Zur Rechtsskepsis in Bernhard Schlinks Der Vorleser", German Life and Letters 55/1: 117-129.

Donahue, William C. (2001): «Illusions of Subtlety: Bernhard Schlink’s Der Vorleser and the Moral Limits of Holocaust Fiction", German Life and Letters 54: 61-81.

Escobar, Federico (2005): «La compulsión por recordar, culparse y exculparse en El lector», Precedente. Revista Juridica: 113-131.

Escobar-Jiménez, Christian (2017): «Silencio y libertad en El lector de Bernhard Schlink: los dilemas de la modernidad", Actio Nova: Revista de Teoría de la Literatura y Literatura Comparada 1: 96-113.

Giordano, Ralph (1990): Die zweite Schuld oder Von der Last Deutscher zu sein, München: Knaur.

Heigenmoser, Manfred (2010): Erläuterungen und Dokumente. Bernhard Schlink Der Vorleser, Stuttgart: Phillip Reclam Verlag.

Jaspers, Karl (1946): Die Schuldfrage, Heidelberg: Lambert Schneider Verlag.

Klemperer, Victor (1995): Ich will Zeugnis ablegen bis zum letzten. Tagebücher 1933-1945. 8 Bde, Berlin: Aufbau Verlag.

Kogon, Eugen (1946): Der SS-Staat-Das System der deutschen Konzentrationslager, München: Verlag Karl Alber.

Lewis, Tess (1997): «Postwar solipsim», New Criticism: 76-77.

LöHndorf, Marion (2002): «Die Banalität der Bösen», Neue Zürcher Zeitung, 28/29.10.

Martín, Juan M. (2011): Victimismo y culpa: la transformación del discurso literario sobre el pasado en la Alemania actual, tesis doctoral, Salamanca: Universidad de Salamanca.

Ost, François (2006): "El reflejo del Derecho en la literatura», DOXA, Cuadernos de Filosofía del Derecho 29: 333-348.

Reviglio, María C. (2020): «El lector / The reader: entre el amor a la literatura y la banalidad del mal», Comunicación y Medios 22: 61-75.

Rubino, Atilio R. (2015): «Los límites de la memoria. Pasado y autobiografía ficcional en Der Voleser de Bernhard Schlink", Hápax 8: 151-163. 
Schlink, Bernhard (1995): Der Vorleser, Zürich: Diogenes Verlag.

Schlink, Bernhard (1997): El lector. Trad. Joan Parra Contreras, Barcelona: Anagrama.

Schlink, Bernhard (2007): Vergangenheitsschuld. Beiträge zu einem deutschen Theme, Zürich: Diogenes Verlag.

Schмiтz, Helmut (2002): «Malen nach zahlen? Bernhard Schlinks Der Vorleser und die Unfähigkeit zu trauern", German Life and Letters 55/3: 296-311.

The Reader (2009). Dir. Stephen Daldry. Perf. Kate Winslet, Ralph Fiennes, David Kross, Bruno Ganz, Burghart Klaußner and Sylvester Groth. TWC.

WirtZ, Thomas (2000): «Immer nur lebenslänglich», Frankfurter Allgemeine Zeitung. 